The VIA Inventory of Strengths, Positive Youth Development, and Moral Education

\author{
University of Alabama
}

Hyemin Han

Author Note

Corresponding author: Hyemin Han (hyemin.han@ua.edu), Educational Psychology

Program, University of Alabama, Box 870231, Tuscaloosa, AL 35487, USA 


\begin{abstract}
The VIA Inventory of Strengths and the VIA model were originally developed to assess and study 24 character strengths. In this paper, I discuss how to properly apply the VIA Inventory and its character strength model to the field of moral education with moral philosophical considerations. First, I review previous factor analysis studies that have consistently reported factors containing candidates for moral virtues, and discuss the systematic structure and organization of VIA character strengths. Second, I discuss several issues related to the VIA model, including lack of previous studies that directly support the moral justifiability of the model and the presence of a fundamental virtue component required for optimal moral functioning in virtue ethics, phronesis, practical wisdom, in the model. Finally, I propose future directions for research on the VIA model in order to address the aforementioned issues and facilitate the application of the model in moral education.
\end{abstract}

Keywords: VIA model, character strengths, virtue, moral education, flourishing, phronesis, factor analysis, Aristotelian moral philosophy 


\section{The VIA Inventory of Strengths, Positive Youth Development, and Moral Education}

Helping students flourishing has been one of the most important goals in the fields of human development and education (Han, 2015a; Seligman, 2011). As an effort to achieve the aforementioned goal, researchers, practitioners, and educators are attempting to apply findings from psychological research, particularly that in the field of positive psychology, to educational programs and activities (Kristjánsson, 2012; Seligman, Gillham, Linkins, Reivich, \& Ernst, 2009; White \& Waters, 2015). Some of them are interested in the application of positive psychology to moral education, particularly those who focus on the development of moral character strengths and positive youth development through moral education (Han, 2015a; Kristjánsson, 2013).

Traditionally, moral education in general aims to develop students' abilities to make better moral judgment through various educational activities, such as dilemma discussions (Kohlberg, 1981, 1984). Recent research on moral education emphasizes that the development of more diverse aspects of human morality, such as moral affect, empathy, motivation, and overall character traits promoting moral behavior in addition to the development of moral reasoning, which has been underscored in traditional moral education, is required for optimal moral functioning (Bebeau, 2002a; Han, 2014b; Sanderse, 2012). Furthermore, moral educators started to focus on how to promote positive youth development and flourishing, which has also been underscored by positive psychologists, by employing ideas and tools in positive psychology to moral education (Han, 2015a, 2015b; Kristjánsson, 2013).

Thus, in this paper, I will consider how to apply concepts and tools developed in positive psychology to moral education, as how to promote positive youth development and flourishing among students have become central topics in moral education. First, I will review the VIA 
Inventory of Strengths and the VIA model (Peterson \& Seligman, 2004), which have been developed by positive psychologists to operationalize and measure character strengths among individuals in a systematic way (Niemiec, 2013). The term, VIA originally stood for "Values in Action". Because the VIA model is one of the most widely used tools to study character strengths that potentially constitute the basis of moral character (Niemiec, 2013), I intend to focus on this model as a framework to connect positive psychology and moral education in this paper. With the examination of the model, I will discuss how to properly apply findings from positive psychology, particularly those based on the VIA model, to moral education. Second, I will examine whether and how the VIA model can inform moral education by reviewing previous studies using the VIA model and inventory. I will focus on whether the model and character strengths included in the model can potentially contribute to moral education while considering moral philosophical accounts. Third, I will discuss the potential limitations in the application of the VIA model to moral education and directions for future research to address the limitations.

\section{The VIA Character Strengths Model}

The VIA character strengths model, which was invented more than a decade ago (Niemiec, 2013), can be a useful tool to systematically understand the nature and organization of character strengths, which constitute the basis of moral character (Althof \& Berkowitz, 2006; Han, 2015a). The VIA model and the VIA inventory were developed to evaluate one's strengths and weaknesses in her characteristic traits and how such strengths and weaknesses influence her well-being, using empirical evidence (C Peterson \& Seligman, 2004). The model defines a character strength as a behavioral and motivational disposition leading to excellence and flourishing, similar to the case of virtue ethics (Hursthouse, 2012), which is pluralistic in nature 
(Park, Peterson, \& Seligman, 2004). Based on this definition, VIA model researchers reviewed literature about character strengths in diverse socio-cultural backgrounds and created the VIA inventory to measure people's strengths and weaknesses in twenty-four characteristic traits, which were extracted from the literature review (Park et al., 2004). These twenty-four traits are: appreciation of beauty and excellence, bravery, citizenship, creativity, curiosity, fairness, forgiveness and mercy, gratitude, hope, humor, integrity, judgment, kindness, leadership, love, love of learning, modesty and humility, persistence, perspective, prudence, self-regulation, social intelligence, spirituality, and zest (Park et al., 2004; C Peterson \& Seligman, 2004).

The model and inventory have been widely utilized to examine character strengths and how they contribute to well-being. Consequently, the VIA institute has acquired data from more than one million participants who have completed the VIA inventory so far. The institute confirmed the reliability and validity of the inventory with the collected dataset (McGrath, 2015). Moreover, various previous studies have consistently demonstrated that the character strengths measured by the VIA inventory significantly contribute to well-being (Martínez-Martí \& Ruch, 2014; Niemiec, 2013; Park et al., 2004; Proyer, Gander, Wyss, \& Ruch, 2011). Several previous studies have employed the VIA inventory to measure the influences of interventions on the development of character strengths (Baer, 2015; Quinlan, Swain, \& Vella-Brodrick, 2012). Furthermore, interestingly, the inventors of the VIA model explicitly stated that they developed the model and extracted character strengths based on various moral philosophical foundations (Park et al., 2004). These points might suggest that the VIA model can help moral educators, who are interested in how to promote the development of moral character among students, better understand and assess character strengths in a systematic way. 


\section{Applicability of the VIA Model in Moral Education}

Moral educators need to carefully examine the nature and functioning of character strengths to improve moral education. In moral education, which emphasizes the importance of moral character, character strengths are deemed to constitute the basis for moral functioning (Crossan, Mazutis, \& Seijts, 2013; Elias, Parker, Kash, Weissberg, \& O’Brien, 2008). Moral psychologists have argued that strong character strengths are necessary to initiate and maintain moral behavior under challenging circumstances (Bebeau, 2002a). For instance, even if we can make a moral decision about what we ought to do to address a moral dilemma, if we do not possess certain character strengths, such as courage, moral behavior could not occur. Furthermore, Aristotelian moral philosophers also underscore the importance of character strengths in moral behavior. According to their perspective, a person's character can be understood as a list of virtues, excellences, and dispositions in behaviors (Hursthouse, 2012) that shape how the person behaves in the world. In addition, good character is a state of appropriate harmony among emotion, reasoning, and behavior that eventually contributes to moral functioning and flourishing according to them (Aristotle, 2000; Homiak, 2015; Malin, Liauw, \& Damon, 2017).

Therefore, the VIA model, which assists systematic research on character strengths, will be able to contribute to moral education by providing conceptual frameworks to understand and tools to assess character strengths. First, the model can provide moral educators and researchers with a framework to understand the structure and organization of character strengths that will potentially constitute the basis of moral virtues and promote moral behavior. Second, the VIA inventory can become a tool to measure such character strengths for assessment and evaluation. 
However, several points related to the moral justifiability of the VIA model and character strengths should be examined while considering its potential contributions to moral education. First, whether character strengths measured by the VIA inventory lead to moral ends can be a fundamental question that should be solved. Let us consider why we need to carefully examine such an issue. Here is one illustrative example demonstrating how the development of character strengths without any moral evaluations, which might result in the pursuit of anti-moral goals, can be problematic (Han, 2015, p. 292):

Unfortunately, these attempts to justify positive psychology and to apply it to moral education cannot be successful without serious and critical considerations from the perspective of moral philosophy. Although positive psychologists can develop a more psychologically sophisticated concept of happiness, this concept may not be any more morally justified than the previous one. For instance, we may imagine the counterexample of a happy and socioemotionally well-adjusted gang member. This gang member is always happy and satisfied with what he is doing and understands the meaning of his job: taking good care of and having good relationships with his cohorts and doing his best for the sake of the vicious purpose of his group. Meanwhile he has his negative affection under control and has strong socio-emotional resiliency.:

Although the gang member possesses and pursues the development of several character strengths, such as kindness and leadership, these character strengths might lead to anti-moral ends, such as successful criminal achievements. The strong character strengths that are possessed by the gang member and required for socio-emotional functioning will assist the member to 
achieve anti-moral goals more successfully. In addition, the gang member is highly likely to utilize such character strengths to achieve a morally unacceptable goal.

Hence, whether the possession and implementations of VIA character strengths result in the realization of morally acceptable and justifiable goals can be a fundamental issue that should at least be addressed before applying the VIA model in moral education. Morality can be defined in a normative way despite the fact that it can be defined in diverse ways. In general, morality can be defined as "a code of conduct that applies to all" and that "protects a larger group," i.e., human beings' welfare, in this way (Bebeau, Rest, \& Narvaez, 1999; Gert \& Gert, 2016; Han, 2014b). If we take into account the concept of morality defined in Aristotelian moral philosophy, which constitutes the basis of this paper, morality guides us to make the most appropriate decision and leads to the flourishing of human beings (Dowie, 2000; Han, 2015b; Kristjánsson, 2014). Unfortunately, no previous studies to date have directly examined whether the possession of VIA character strengths contribute to moral dispositions and moral behavioral outcomes.

Furthermore, how to appropriately implement character strengths is also a fundamental issue in optimal moral functioning. Let us consider a character strength, courage, as an example. In Nichomachaen Ethics (Aristotle, 2000), extreme courage, rashness, as well as deficiency of courage, cowardice, are treated as vices, not virtues, although courage is a fundamental virtue. Thus, we have to figure out the golden mean, courage as a moral virtue. The golden mean, courage, between those two extreme ends, rashness and cowardice, is not a mere arithmetic mean. Instead, a careful evaluation of situational factors is necessary to determine the appropriate degree of a character strength, the golden mean, that shall be implemented. In fact, previous research using the VIA model warned that possessing extremely strong character strengths in certain domains might produce negative behavioral and mental outcomes. Freidlin, 
Littman-Ovadia, and Niemiec (2017) reported that both the overuse and underuse of character strengths were associated with mental issues, such as depression and social anxiety; instead, exercising the optimal degree of character strengths significantly predicted satisfaction and flourishing. In addition, possible conflicts between individual character strengths should also be considered. For example, when we see that our family member is behaving illegally, we may experience a conflict between the strength of love (to a family member) and the strength of fairness; fairness may ask us to report the police while love may ask us not to do so. Therefore, we need to consider how to determine which character strength should be prioritized to appropriately address a specific situation for optimal moral functioning.

Thus, we also need to examine whether the VIA model can address the aforementioned issue pertaining to the appropriate implementation of character strengths. In Aristotelian moral philosophy, such an issue about finding the golden mean and making the most appropriate decision is addressed by phronesis. Phronesis refers to practical wisdom in Aristotelian moral philosophy. It enables us to avoid to choose any extreme ends (e.g., cowardice vs. recklessness), to know the golden mean (e.g., courage), to find the most appropriate solution, and to behave appropriately and morally (Han, 2015a; Kristjánsson, 2013, 2014). From Aristotelian perspective, individual character strengths, such as courage and friendliness, can be understood as first-order virtues. Unlike the individual first-order virtues, phronesis is regarded as a fundamental second-order virtue. A second-order virtue serves as a moderator and plays a corrective role in finding the golden mean in various situations while avoiding extreme ends, either the overuse or underuse of first-order virtues, and addressing conflicts between different first-order virtues (Curzer, 1995; Han, 2015a; Kristjánsson, 2010). 
Hence, whether the VIA model includes character strength components that work as second-order virtues can be one of central issues in the examination of its applicability in moral education. At least, the VIA model needs to include character strengths that can be considered as candidates for second-order virtues, phronesis in particular, that help us find the golden mean to appropriately solve a problematic situation while preventing either the underuse or overuse of character strengths and addressing conflicts between them. If such a requirement could not be fulfilled, moral educators will not be able to study and assess second-order virtues that play fundamental roles in optimal moral functioning and producing morally appropriate dispositions and behavioral outcomes with the VIA model. Unfortunately, no previous studies to date have directly examined such a point.

\section{Reviewing Previous Factor Analyses}

To examine whether the VIA model contains character strengths contributing to moral functioning, and finally can contribute to the studies of moral education, I reviewed previous factor analyses. If the VIA model has morality-related features, character strengths potentially associated with such features are supposed to be consistently clustered into factor(s) across studies. In addition, such reported factor(s) should contain candidates for first- and second-order virtues. More specifically, first, character strengths associated first-order virtues, such as those suggested by virtue moral philosophers (e.g. bravery, kindness, gratitude) (Carr, 2014; Kristjánsson, 2015), should be consistently extracted as factor(s). Second, in addition to factor(s) consisting of first-order moral virtues, factor(s) associated with second-order virtues, particularly phronesis, should also be extracted as factor(s). As I discussed in the introduction, the mere possession of first-order virtues without phronesis could not lead to optimal moral functioning and flourishing according to Aristotelian virtue ethics, because phronesis is required to produce 
the most appropriate decision and behavioral outcome within a specific context when different first-order virtues and values are conflicting with each other (Han, 2015a; Kristjánsson, 2014). If we can repeatedly find these factors containing character strengths related to both first- and second-order from previous factor analyses of the VIA model, we will be able to say that the VIA model possesses the systematic nature of moral virtues, and its applicability to moral education is supported from the perspective of virtue ethics.

Based on the aforementioned points, I focused on two points while reviewing previous factor analyses. First, I examined whether factors that contain morality-related character strengths, character strengths seemingly associated with individual first-order virtues, were extracted as factors in the previous analyses. Second, I reviewed whether the model includes the factors of character strengths that are deemed to play corrective and moderating roles, i.e., candidates for second-order virtues, such as phronesis, that adjust the strength of the exercise of each first-order virtue and help us make the most appropriate moral decisions.

\section{Searching for Factor(s) with First-order Virtues}

\section{$<$ Place Table 1 about here>}

First, I searched for factor(s) containing character strengths deemed to be associated with first-order moral virtues, i.e., individual virtues in particular domains (e.g., courage and friendliness), from the VIA character strengths. I first reviewed McGrath's (2014) factor analysis with a large dataset $(N=458,998)$. This large dataset was collected from " 458,998 adults who completed the VIA-IS instrument online between 2005 and 2008 at the Authentic Happiness website, or between 2008 and 2001 at the VIA Institute on Character website (McGrath, 2014, p. 7)." Because the institute suggests researchers who intend to use the VIA inventory use the survey form on its webpage (VIA Institute on Character, 2018a), the large dataset is the largest 
and most comprehensive dataset collected from diverse populations. As I referred to the moral philosophical accounts that defined morality as a code of conduct protects and pursues all human beings' welfare and flourishing in the introduction (Bebeau et al., 1999; Dowie, 2000; Gert \& Gert, 2016; Han, 2014a, 2015b; Kristjánsson, 2014), I attempted to find other-oriented character strength factors - i.e., interpersonal and theological strength factors in McGrath (2014). The interpersonal strength factor consisted of fairness, kindness, teamwork, leadership, and forgiveness, and the theological strengths factor consisted of zest, hope, gratitude, spirituality, and love (McGrath, 2014) (see Table 1).

Then, I examined in which factor each identified candidate character strength was included in other previous factor analyses (Brdar \& Kashdan, 2010; Littman-Ovadia \& Lavy, 2012; Macdonald, Bore, \& Munro, 2008; McGrath \& Walker, 2016; Christopher Peterson, Park, Pole, D’Andrea, \& Seligman, 2008; Ruch et al., 2010; Shryack, Steger, Krueger, \& Kallie, 2010; Singh \& Choubisa, 2010). I found eight previous factor analysis studies from the list of reviewed articles in McGrath (2014) and the VIA Institute on Character webpage containing a list of published articles (VIA Institute on Character, 2018b). Among the aforementioned character strengths, kindness, teamwork, leadership, and gratitude were consistently categorized as otheroriented strengths across the eight previous factor analyses (see Table 1).

\section{Searching for Factor(s) with Second-order Virtues}

Second, I attempted to find which character strengths can be considered as candidates for second-order virtues, particularly phronesis, from the previous factor analyses. Similar to the prior examination of candidates for first-order virtues, I sought candidates from McGrath's (2014) large-scale analysis. I particularly focused on the character strengths of restraint in his analysis, because phronesis in virtue ethics plays a corrective role in the exercise of first-order 
virtues (Han, 2015a; Kristjánsson, 2014), and it ultimately deal with the morally appropriate control of self with practical wisdom (Coope, 2012; Tabachnick, 2004). Consequently, prudence, perseverance, self-regulation, judgment, and honesty, which were clustered into the restraint factor, were found from his factor analysis. Among these strengths, prudence, self-regulation, judgment, and honesty were consistently classified as strengths associated with controlling the self through practical reasoning in the aforementioned eight other previous factor analyses (see Table 1).

Consequently, I found that previous factor analysis studies have consistently reported the presence of factors associated with candidates for first- and second-order virtues. More specifically, interpersonal and theological factors are deemed to be associated with first-order virtues, and the restraint factor is deemed to be associated with second-order virtues in McGrath's (2014) large-scale factor analysis. In addition, I was able to identify that factors that are potentially associated with first- and second-order virtues were also extracted in other previous factor analysis studies as well. Hence, the VIA model and inventory might be able to properly explain the nature of moral virtues, and assess character strengths associated with moral virtues proposed in virtue ethics, which underscores both first- and second-level virtues in moral functioning, in a systematic manner. Findings from the previous factor analysis studies can support the potential applicability of the VIA model to the research on and practice of moral education.

\section{Some Remaining Issues}

Although the VIA model was deemed to entail potential candidates for first-order and second-order virtues, we should also carefully consider potential limitations of this model. Let us consider whether individual VIA character strengths are justifiable from the perspective of 
Aristotelian moral philosophy. While my review of the previous factor analyses showed that several character strengths can be candidates for first-order and second-order virtues, it is still unclear whether such character strengths can eventually lead to moral ends.

First, whether possessing strong character strengths that are potentially associated with first-order virtues helps the generation of moral dispositions and moral behavioral outcomes is still unclear due to lack of previous research directly addressing this question. For instance, let us consider this brief hypothetical situation. A person received a high score for the character strength of "bravery" on the VIA inventory. Of course, courage, one of fundamental first-order moral virtues, is required to initiate and sustain moral behavior (Bebeau, 2002b). However, the mere possession of this character strength per se, which is measured by the VIA inventory, might not necessary motivate us to engage in moral behavior. Bravery might enable a villain to achieve its anti-moral purpose, instead. Although my review demonstrated that previous factor analyses consistently reported character strength factors that can be understood as candidates for various important first-order moral virtues, whether they necessarily lead to moral dispositions and moral behavioral outcomes is still unclear.

Second, whether character strengths that are deemed to be candidates for second-order virtues, such as prudence, self-regulation, judgment, and honesty, actually work as second-order virtues in the reality as a way explained in virtue ethics is also still unclear. Although my review of previous factor analyses suggest that some character strengths consistently clustered into a factor are possibly associated with second-order virtues, the character strengths might not play corrective and moderating roles for the optimal functioning of first-order virtues. For example, there have been no previous research about whether strong prudence, self-regulation, judgment, and honesty prevent either underuse or overuse of other character strengths (Freidlin et al., 
2017), and are associated with developed moral functioning, such as sophisticated reasoning and judgment in the domain of morality (Rest, Narvaez, Bebeau, \& Thoma, 1999; Walker, 1980). Furthermore, although the aforementioned VIA character strengths potentially associated with decision-making skills may be candidates for phronesis, the mere exercise of such strengths does not necessarily lead to morally appropriate results. Let us consider the illustrative example of the well-regulated gang member once again (Han, 2015a). Although the gang member might possess strong character strengths considered as candidates for second-order virtues, the exercise of the character strengths is likely to result in well-regulated but vicious behavioral outcomes, not morally appropriate outcomes. In fact, May (2017) argued that sophisticated and developed reasoning abilities may serve in anti-moral ways, such as moral rationalization to justify one's anti-moral behavior. Likewise, vicious deeds done by the aforementioned gang member are likely to be much more negative and successful compared with those done by a gang member who does not possess the aforementioned character strengths. Due to these issues, it is still unclear whether the VIA model contains any character strength(es) that properly function as phronesis.

\section{Future Directions}

How will we be able to address the aforementioned issues in future research? First, let us consider ideas for future studies for the moral justification of the VIA character strength. We can examine relationships between VIA character strengths and moral developmental indicators, for example, the Defining Issues Test (DIT) score (Rest et al., 1999) measuring the development of moral reasoning, or the Moral Competence Test (MCT) score (Lind, 2008) testing whether one can make consistent moral decisions across different situations, in order to examine whether the character strengths are associated with moral development. We can consider employing more 
recently developed tools assessing Aristotelian virtues and the development of moral character (Arthur et al., 2014; Curren \& Kotzee, 2014; Morgan, Gulliford, \& Kristjánsson, 2014). Moral development in this context implies moral development from the perspective Aristotelian moral philosophy and character development (Han, 2015b). There are two phases of moral development from the Aristotelian perspective: internalization and habituation of virtues and cultivation of phronesis through deliberation (Sanderse, 2014). For example, improvement of character strengths considered as candidates for first-order virtues is possibly associated with the first phase of Aristotelian moral development, the internalization and habituation of virtues. Moreover, sophistication of character strengths considered as candidates for second-order virtues can be related to the second phase, the cultivation of phronesis. Thus, the suggested future studies will inform us whether pursuing the development of VIA character strengths, which are deem to be associated with moral character strengths and virtues, in moral education can eventually contribute to moral development and lead to moral ends.

Second, we will need to conduct studies examining whether some character strengths that seem to be candidates for second-order virtues - for example, self-regulation, judgment, and honesty - moderate the performance of other character strengths, candidates for first-order virtues - for example, bravery and kindness. Because second-order virtues, phronesis in particular, play a corrective role, the moderation of the exercise of individual first-order virtues to produce the most appropriate disposition and behavioral outcome in a given situation, according to virtue ethics, candidate character strengths of second-order virtues in the VIA model are also expected to demonstrate the similar moderating effect. If we find that the candidate character strengths of second-order virtues positively moderate the relationship between candidate character strength of first-order virtues and positive behavioral and 
developmental outcomes, for example, service engagement (Han, Kim, Jeong, \& Cohen, 2017; Malin, Ballard, \& Damon, 2015; Malin, Han, \& Liauw, 2017) and meaning in life (Han, Liauw, \& Kuntz, 2018; Steger, Frazier, Oishi, \& Kaler, 2006), we can have evidence supporting that such character strengths may actually function as second-order virtues.

Once future research successfully addresses the remaining issues, moral educators and researchers in the field of moral education will be able to utilize the VIA model and inventory to systematically assess character strengths that constitute the basis of optimal moral functioning and flourishing among students. If we discover that character strengths in the VIA model are strongly associated with moral developmental indicators and moral virtues including both firstand second-order virtues, researchers and educators in the field of moral education will have a tool for research and evaluation of educational programs that is empirically supported (White \& Waters, 2015). If stronger VIA characters strengths are found to be associated with more developed moral reasoning and practical wisdom, and finally, flourishing, we will be able to assess students' character strengths constituting the basis of moral functioning in a more systematic manner (Shryack et al., 2010). In addition, the VIA model will help researchers and moral educators better assess and understand more diverse aspects of moral character strengths (Kern, Waters, Adler, \& White, 2015), which could not be properly assessed by previous moral psychological tools focusing on specific aspects of moral functioning, such as the DIT focusing on moral reasoning and the MCT focusing on moral competence (Lind, 2008; Thoma, 2006).

\section{Conclusion}

In this paper, I briefly discussed the applicability of the VIA model within in moral education from the perspective of Aristotelian moral philosophy as the analytic framework. My review of previous factor analyses demonstrated that the VIA model seemingly includes factors 
that contain character strengths that might be considered as candidates for first- and second-order virtues. However, future research should attempt to address several issues discussed in this paper that arise from the moral philosophical perspective, because the previous factor analyses per se do not necessarily confirm that the reported character strength factors function as first- and second-order virtues in a way explained in Aristotelian moral philosophy. Once future research shows that the VIA model contains character strengths promote optimal moral functioning and flourishing in the reality, the model will become a more robust research program that contributes to studies not only in positive psychology, but also in moral psychology and moral education.

\section{Acknowledgements}

I thank Robert McGrath for his psychological comments and Joshua May for his philosophical comments on an earlier version of the manuscript. I also appreciate invaluable comments from the associate editor, Stephen Schueller, and anonymous reviewers. 


\section{References}

Althof, W., \& Berkowitz, M. W. (2006). Moral education and character education: their relationship and roles in citizenship education. Journal of Moral Education, 35(4), 495518. doi:10.1080/03057240601012204

Aristotle. (2000). Nicomachean Ethics. New York, NY: Cambridge University Press.

Arthur, J., Kristjansson, K., Thomas, H., Holdsworth, M., Confalonieri, L. B., \& Qiu, T. (2014). Virtuous character for the practice of law: research report. Birmingham, UK. Retrieved from http://epapers.bham.ac.uk/1953/1/Virtuous_Character_for_the_Practice_of_Law.pdf

Baer, R. (2015). Ethics, Values, Virtues, and Character Strengths in Mindfulness-Based Interventions: a Psychological Science Perspective. Mindfulness, 6(4), 956-969. doi:10.1007/s12671-015-0419-2

Bebeau, M. J. (2002a). The Defining Issues Test and the Four Component Model: Contributions to professional education. Journal of Moral Education, 31(3), 271-295. doi:10.1080/0305724022000008115

Bebeau, M. J. (2002b). The defining issues test and the four component model: contributions to professional education. Journal of Moral Education, 31, 271-295. doi:10.1080/0305724022000008115

Bebeau, M. J., Rest, J. R., \& Narvaez, D. (1999). Beyond the promise: A perspective on research in moral education. Educational Researcher, 28(4), 18-26.

Brdar, I., \& Kashdan, T. B. (2010). Character strengths and well-being in Croatia: An empirical investigation of structure and correlates. Journal of Research in Personality, 44(1), 151154. doi:10.1016/j.jrp.2009.12.001

Carr, D. (2014). Is gratitude a moral virtue? Philosophical Studies. doi:10.1007/s11098-014- 
0360-6

Coope, U. (2012). Why does Aristotle Think that Ethical Virtue is Required for Practical Wisdom? Phronesis, 57(2), 142-163. doi:10.1163/156852812X628998

Crossan, M., Mazutis, D., \& Seijts, G. (2013). In Search of Virtue: The Role of Virtues, Values and Character Strengths in Ethical Decision Making. Journal of Business Ethics, 113(4), 567-581. doi:10.1007/s10551-013-1680-8

Curren, R., \& Kotzee, B. (2014). Can virtue be measured? Theory and Research in Education, 12, 266-282. doi:10.1177/1477878514545205

Curzer, H. J. (1995). Aristotle's Account of the Virtue of Justice. Apeiron: A Journal for Ancient Philosophy and Science, 28(3), 207-238.

Curzer, H. J. (2014). Tweaking the four-component model. Journal of Moral Education, 43(1), 104-123. doi:10.1080/03057240.2014.888991

Dowie, A. (2000). Phronesis or "practical wisdom" in medical education. Medical Teacher, 22(3), 240-241. doi:10.1080/01421590050006188

Elias, M. J., Parker, S. J., Kash, V. M., Weissberg, R. P., \& O’Brien, M. U. (2008). Social and emotional learning, moral education, and character education: A comparative analysis and a view toward convergence. In L. P. Nucci \& D. Narvaez (Eds.), Handbook of Moral and Character education (pp. 248-266). New York, NY: Routledge.

Freidlin, P., Littman-Ovadia, H., \& Niemiec, R. M. (2017). Positive psychopathology: Social anxiety via character strengths underuse and overuse. Personality and Individual Differences, 108, 50-54. doi:10.1016/j.paid.2016.12.003

Gert, B., \& Gert, J. (2016). The Definition of Morality. In Edward N. Zalta (Ed.), The Stanford Encyclopedia of Philosophy. Retrieved from https://plato.stanford.edu/entries/morality- 
definition/

Han, H. (2014a). Analysing theoretical frameworks of moral education through Lakatos's philosophy of science. Journal of Moral Education, 43(1), 32-53. doi:10.1080/03057240.2014.893422

Han, H. (2014b). Analyzing theoretical frameworks of moral education through Lakatos's philosophy of science. Journal of Moral Education, 43(1), 32-53. doi: $10.1080 / 03057240.2014 .893422$

Han, H. (2015a). Purpose as a moral virtue for flourishing. Journal of Moral Education, 44(3), 291-309. doi:10.1080/03057240.2015.1040383

Han, H. (2015b). Virtue ethics, positive psychology, and a new model of science and engineering ethics education. Science and Engineering Ethics, 21(2), 441-460. doi:10.1007/s11948014-9539-7

Han, H., Kim, J., Jeong, C., \& Cohen, G. L. (2017). Attainable and Relevant Moral Exemplars Are More Effective than Extraordinary Exemplars in Promoting Voluntary Service Engagement. Frontiers in Psychology, 8, 283. doi:10.3389/fpsyg.2017.00283

Han, H., Liauw, I., \& Kuntz, A. F. (2018). Moral Identity Predicts the Development of Presence of Meaning during Emerging Adulthood. Emerging Adulthood. doi:10.1177/2167696818758735

Homiak, M. (2015). Moral character. In E. N. Zalta (Ed.), Stanford Encyclopedia of Philosophy. Retrieved from https://plato.stanford.edu/entries/moral-character/

Hursthouse, R. (2012). Virtue Ethics. In E. N. Zalta (Ed.), Stanford Encyclopedia of Philosophy. Retrieved from http://plato.stanford.edu/entries/ethics-virtue/

Kern, M. L., Waters, L. E., Adler, A., \& White, M. A. (2015). A multidimensional approach to 
measuring well-being in students: Application of the PERMA framework. The Journal of Positive Psychology, 10(3), 262-271. doi:10.1080/17439760.2014.936962

Kohlberg, L. (1981). The philosophy of moral development: Moral stages and the idea of justice. San Francisco: Harper \& Row.

Kohlberg, L. (1984). The psychology of moral development: the nature and validity of moral stages. San Francisco: Harper \& Row.

Kristjánsson, K. (2010). The Trouble with Ambivalent Emotions. Philosophy. doi:10.1017/S0031819110000434

Kristjánsson, K. (2012). Positive Psychology and Positive Education: Old Wine in New Bottles? Educational Psychologist, 47(2), 86-105. doi:10.1080/00461520.2011.610678

Kristjánsson, K. (2013). Virtues and vices in positive psychology: A philosophical critique. New York, NY: Cambridge University Press.

Kristjánsson, K. (2014). Phronesis and moral education: Treading beyond the truisms. Theory and Research in Education. doi:10.1177/1477878514530244

Kristjánsson, K. (2015). An Aristotelian Virtue of Gratitude. Topoi, 34(2), 499-511. doi:10.1007/s11245-013-9213-8

Lind, G. (2008). The meaning and measurement of moral judgment competence revisited: A dual-aspect model. In D. Fasko \& W. Willis (Eds.), Contemporary Philosophical and Psychological Perspectives on Moral Development and Education (pp. 185-220). Cresskill, NJ: Hampton Press.

Littman-Ovadia, H., \& Lavy, S. (2012). Character Strengths in Israel. European Journal of Psychological Assessment, 28(1), 41-50. doi:10.1027/1015-5759/a000089

Macdonald, C., Bore, M., \& Munro, D. (2008). Values in action scale and the Big 5: An 
empirical indication of structure. Journal of Research in Personality, 42(4), 787-799. doi:10.1016/j.jrp.2007.10.003

Malin, H., Ballard, P. J., \& Damon, W . (2015). Civic purpose: An integrated construct for understanding civic development in adolescence. Human Development, 58(2), 103-130. doi:10.1159/000381655

Malin, H., Han, H., \& Liauw, I. (2017). Civic purpose in late adolescence: Factors that prevent decline in civic engagement after high school. Developmental Psychology. doi: $10.1037 /$ dev0000322

Malin, H., Liauw, I., \& Damon, W. (2017). Purpose and Character Development in Early Adolescence. Journal of Youth and Adolescence, 46(6), 1200-1215. doi:10.1007/s10964017-0642-3

Martínez-Martí, M. L., \& Ruch, W. (2014). Character strengths and well-being across the life span: data from a representative sample of German-speaking adults living in Switzerland. Frontiers in Psychology, 5. doi:10.3389/fpsyg.2014.01253

May, J. (2017). Getting Less Cynical about Virtue. In W. Sinnott-Armstrong \& C. Miller (Eds.), Moral Psychology, Volume 5 (pp. 45-52). Cambridge, MA: MIT Press.

McGrath, R. E. (2014). Scale- and Item-Level Factor Analyses of the VIA Inventory of Strengths. Assessment, 21(1), 4-14. doi:10.1177/1073191112450612

McGrath, R. E. (2015). Integrating psychological and cultural perspectives on virtue: The hierarchical structure of character strengths. The Journal of Positive Psychology, 10(5), 407-424. doi:10.1080/17439760.2014.994222

McGrath, R. E., \& Walker, D. I. (2016). Factor structure of character strengths in youth: Consistency across ages and measures. Journal of Moral Education, 45(4), 400-418. 
doi:10.1080/03057240.2016.1213709

Meindl, P., Quirk, A., \& Graham, J. (2017). Best Practices for School-Based Moral Education. Policy Insights from the Behavioral and Brain Sciences, 237273221774708. doi: $10.1177 / 2372732217747087$

Morgan, B., Gulliford, L., \& Kristjánsson, K. (2014). Gratitude in the UK: A new prototype analysis and a cross-cultural comparison. The Journal of Positive Psychology, 9, 281-294. doi:10.1080/17439760.2014.898321

Niemiec, R. M. (2013). VIA character strengths: Research and practice (the first 10 years). In H. H. Knoop \& A. D. Fave (Eds.), Well-Being and Cultures: Perspectives 11 from Positive Psychology, Cross-Cultural Advancements in Positive Psychology 3 (pp. 11-29).

Dordrecht, The Netherlands: Springer Science+Business Media.

Park, N., Peterson, C., \& Seligman, M. E. P. (2004). Strengths of Character and Well-Being. Journal of Social and Clinical Psychology, 23(5), 603-619. doi: $10.1521 /$ jscp.23.5.603.50748

Peterson, C., Park, N., Pole, N., D’Andrea, W., \& Seligman, M. E. P. (2008). Strengths of character and posttraumatic growth. Journal of Traumatic Stress, 21(2), 214-217. doi:10.1002/jts.20332

Peterson, C., \& Seligman, M. E. P. (2004). Character strengths and virtues: A handbook and classification. New York, NY: Oxford University Press.

Proyer, R. T., Gander, F., Wyss, T., \& Ruch, W. (2011). The Relation of Character Strengths to Past, Present, and Future Life Satisfaction among German-Speaking Women. Applied Psychology: Health and Well-Being, 3(3), 370-384. doi:10.1111/j.1758-0854.2011.01060.x

Quinlan, D., Swain, N., \& Vella-Brodrick, D. A. (2012). Character Strengths Interventions: 
Building on What We Know for Improved Outcomes. Journal of Happiness Studies, 13(6), 1145-1163. doi:10.1007/s10902-011-9311-5

Rest, J. R., Narvaez, D., Bebeau, M., \& Thoma, S. (1999). A Neo-Kohlbergian approach: The DIT and schema theory. Educational Psychology Review, 11(4), 291-324. doi:10.1023/a:1022053215271

Ruch, W., Proyer, R. T., Harzer, C., Park, N., Peterson, C., \& Seligman, M. E. P. (2010). Values in Action Inventory of Strengths (VIA-IS). Journal of Individual Differences, 31(3), 138149. doi:10.1027/1614-0001/a000022

Sanderse, W. (2012). Character Education: A Neo-Aristotelian Approach to the Philosophy, Psychology and Education of Virtue. Delft, The Netherlands: Eburon Academic Publishers. Sanderse, W. (2014). An Aristotelian Model of Moral Development. Journal of Philosophy of Education. doi:10.1111/1467-9752.12109

Seligman, M. E. P. (2011). Flourish: A visionary new understanding of happiness and wellbeing. Flourish: A Visionary New Understanding of Happiness and Well-Being.

Seligman, M. E. P., Gillham, J., Linkins, M., Reivich, K., \& Ernst, R. M. (2009). Positive education: positive psychology and classroom interventions. Oxford Review of Education. doi:10.1080/03054980902934563

Shryack, J., Steger, M. F., Krueger, R. F., \& Kallie, C. S. (2010). The structure of virtue: An empirical investigation of the dimensionality of the virtues in action inventory of strengths. Personality and Individual Differences, 48(6), 714-719. doi:10.1016/j.paid.2010.01.007

Singh, K., \& Choubisa, R. (2010). Empirical validation of values in action-inventory of strengths (VIA-IS) in Indian context. Psychological Studies, 55(2), 151-158. doi:10.1007/s12646010-0015-4 
Steger, M. F., Frazier, P., Oishi, S., \& Kaler, M. (2006). The meaning in life questionnaire: Assessing the presence of and search for meaning in life. Journal of Counseling Psychology, 53(1), 80-93. doi:10.1037/0022-0167.53.1.80

Tabachnick, D. E. (2004). Phronesis, Democracy and Technology. Canadian Journal of Political Science/Revue Canadienne de Science Politique, 37(4). doi:10.1017/S0008423904990191

Thoma, S. J. (2006). Research on the Defining Issues Test. In M. Killen \& J. G. Smetana (Eds.), Handbook of Moral Development (pp. 67-91). Mahwah, NJ: Psychology Press.

VIA Institute on Character. (2018a). The VIA Survey. Retrieved from http://www.viacharacter.org/www/Character-Strengths-Survey

VIA Institute on Character. (2018b). Universality, Prevalence, And General Findings. Retrieved from http://www.viacharacter.org/www/Research/Universality-Prevalence-and-GeneralFindings

Walker, L. J. (1980). Cognitive and perspective-Taking prerequisites for moral development. Child Development, 51, 131-139. doi:10.2307/1129599

White, M. A., \& Waters, L. E. (2015). A case study of "The Good School:" Examples of the use of Peterson's strengths-based approach with students. The Journal of Positive Psychology, 10(1), 69-76. doi:10.1080/17439760.2014.920408 
Tables

Table 1

Character strengths deemed to be associated with first-and second-order virtues from the review of previous factor analyses

\begin{tabular}{|c|c|c|c|c|c|c|c|c|c|}
\hline & $\begin{array}{l}\text { McGrath } \\
\text { (2014) }\end{array}$ & $\begin{array}{c}\text { McGrath and } \\
\text { Walker (2016) }\end{array}$ & $\begin{array}{c}\text { Brdar and } \\
\text { Kashdan (2010) }\end{array}$ & $\begin{array}{l}\text { Peterson et al. } \\
\quad(2008)\end{array}$ & $\begin{array}{l}\text { Macdonald et al. } \\
\text { (2008) }\end{array}$ & $\begin{array}{l}\text { Ruch et al. } \\
\text { (2010) }\end{array}$ & $\begin{array}{c}\text { Singh and } \\
\text { Choubisa (2010) }\end{array}$ & Shryack et al. (2010) & $\begin{array}{l}\text { Littman-Ovadia } \\
\text { and Lavy (2012) }\end{array}$ \\
\hline \multicolumn{10}{|c|}{ Strengths deemed to be related with first-order moral virtues } \\
\hline Fairness & Interpersonal & Self-control & Interpersonal & Temperance & Niceness & Interpersonal & Civic & Sociability & Emotional \\
\hline Kindness & Interpersonal & Other-oriented & Interpersonal & Interpersonal & Niceness & Interpersonal & Interpersonal & Sociability & Emotional \\
\hline Teamwork & Interpersonal & Vitality & Interpersonal & Interpersonal & Positivity & Interpersonal & Civic & Sociability & Emotional \\
\hline Leadership & Interpersonal & Vitality & Interpersonal & Interpersonal & Positivity & Interpersonal & Civic & Sociability & Emotional \\
\hline Forgiveness & Interpersonal & Other-oriented & Interpersonal & Temperance & Niceness & Interpersonal & Theological & Sociability & Emotional \\
\hline Zest & Theological & Vitality & Vitality & Transcendence & Positivity & Emotional & Self-assurance & Agency/self-assuredness & Intellectual \\
\hline Hope & Theological & Vitality & Vitality & Transcendence & Positivity & Emotional & Self-assurance & Agency/self-assuredness & Theological \\
\hline Gratitude & Theological & Vitality & Interpersonal & Transcendence & Niceness & Theological & Theological & Sociability & Theological \\
\hline Spirituality & Theological & Vitality & Cautiousness & Transcendence & Niceness & Theological & Self-assurance & & Theological \\
\hline Love & Theological & Vitality & Interpersonal & Interpersonal & Positivity & Emotional & Theological & Sociability & Emotional \\
\hline \multicolumn{10}{|c|}{ Strengths deemed to be related with second-order moral virtues } \\
\hline Prudence & Restraint & Self-control & Fortitude & Temperance & Conscientiousness & Restraint & Civic & Conscientiousness & Restraint \\
\hline Perseverance & Restraint & Vitality & Cautiousness & Fortitude & Conscientiousness & Restraint & Self-assurance & Conscientiousness & Restraint \\
\hline Self-regulation & Restraint & Self-control & Cautiousness & Fortitude & Conscientiousness & Restraint & Self-assurance & Conscientiousness & Restraint \\
\hline Judgment & Restraint & Self-control & Fortitude & Fortitude & Conscientiousness & Intellectual & Intellectual & Agency/Self-assuredness & Restraint \\
\hline Honesty & Restraint & Self-control & Cautiousness & Fortitude & Conscientiousness & Restraint & Civic & Conscientiousness & Restraint \\
\hline
\end{tabular}

Note. Character strengths categorized in similar categories were highlighted with the same color. 